\title{
Perceptions On The Use Of A Corporate Business Incubator To Enhance Knowledge Management At Eskom
}

PD Steyn \& ASA du Toit

Centre for Information and Knowledge Management, University of Johannesburg

\begin{abstract}
The knowledge economy impacts on the way enterprises should address their business requirements, forcing many of them to review the potential mechanisms they could employ to improve their competitive advantage. The business incubator approach is one such mechanism. This article explores the application of knowledge management, knowledge creation and innovation in a corporate incubator. It focuses on the process of knowledge management, to ensure that a culture and appropriate strategies conducive to enhancing knowledge creation are developed in an enterprise. Innovation as a strategic imperative is considered, as well as the challenge of driving it within an enterprise. The purpose of this empirical survey was to determine whether the corporate incubator model applied by Eskom conforms to the attributes of knowledge management, knowledge creation and innovation, and whether the synergies to be exploited amongst these disciplines can be harnessed to give Eskom a competitive advantage.
\end{abstract}

JEL D80, 83

\section{1 \\ Introduction}

The knowledge economy has started to impact on the way enterprises should be addressing their business requirements, forcing many of them to review the potential mechanisms they could employ to improve their competitive advantage. In the USA and, to some extent, in Europe, the business incubator approach, with its various models, is acknowledged as one such mechanism. It is able to improve time-to-market for new products, as well as enabling a network of experts to be in constant communication. Venture funding is available for supporting the incubators, which are important in allowing intra-enterprise creative talent to be harnessed

The application of knowledge management and knowledge creation in a corporate incubator at Eskom requires the successful initial incubation of ideas in an environment conducive to and supportive of knowledge management, innovative thinking and creativity. These elements must then be captured within the incubator, where there is the potential for their development into viable competitive products and services. This research therefore focuses on the perceptions by Eskom employees of the role of knowledge creation and knowledge management at Eskom. This includes their opinions on how the corporate incubator could complement the relationship between knowledge creation, knowledge management and innovation.

\section{2}

\section{Knowledge management and innovation}

Innovation can be defined as a completed knowledge process life-cycle event. The cycle begins with a problem that emerges from a business process, moves through knowledge production, and concludes with the incorporation of knowledge structures (Firestone, 2003). 
One characteristic of innovation is that it has an impact on business process behaviour. Nonaka and Takeuchi (1995) regard the mobilisation and conversion of tacit knowledge as the key to successful innovation processes. Innovation is the creation of new knowledge. However, knowledge creation itself is not always innovative. Enterprises cannot create knowledge without people, so they should support and provide contexts for creative individuals where they can create knowledge. Innovation is the interaction of tacit and explicit knowledge and their mutual interchange in the creative activities of human beings.

In the knowledge economy, markets transform or become obsolete so rapidly that prominence in any particular market segment could actually be detrimental to survival. The ability to constantly reinvent the business and to innovate is crucial to the knowledge economy. In addition, globalisation has removed the barriers between local and regional markets, while new market entrants have impeded attempts at total dominance by any one player. In this environment, it is vital to be constantly alert. In addition, strategy cannot depend on an enterprise's products and markets, but has to rely on the dynamics of its behaviour. It is essential, therefore, to recognise and enhance the more complex capabilities that distinguish an enterprise within the marketplace, such as its culture and processes.

According to post-industrial social theory, the provision of services will grow and the importance of the production of goods will decline, with knowledge becoming the basis of economic growth and productivity. This will be manifested in an increased number of managerial or white-collar workers. However, the distinction between services and goods is becoming blurred, because knowledge is obviously the prominent factor in terms of economic activity (Burton-Jones, 1999). On the other hand, Drucker (1998:1) states that "...[t]wenty years from now the typical large business will have half the levels of management and one-third the managers of its counterparts today. Specialists brought together in task forces that cut across traditional departments...will do the work".
These two statements are not contradictory. Drucker's assumption is correct and the growth of white-collar workers envisaged by Burton-Jones is, in fact, true in terms of the increased numbers of knowledge workers. Such is the impact of the knowledge worker that business is going to become informationbased, with a swift transition from the use of manual and administrative workers to that of knowledge workers. This is a prerequisite for any enterprise wishing to become innovative and entrepreneurial.

Information is generally accepted to be data with attributes, relevance and purpose. Converting it into information requires knowledge, which, according to Drucker (1998: 5 ), is a specialised process of transformation also requiring knowledge. Specialists in this process are needed in the operational areas to carry out the relevant procedures, while only a small support team for ancillary activities like legal and information technology support would be necessary. This means fewer organisational levels and, in theory, swifter intra-enterprise communications and information-sharing. However, knowledge and its management will not, on their own, deliver the results necessary for obtaining and maintaining sustainable competitive advantages in the knowledge economy. Knowledge and innovation are complementary issues, and their impact on the enterprise should not be viewed as separate and mutually exclusive.

Murray and Rowan (2000: 2) put this in perspective with their view that, in the knowledge economy, innovation, which is research-based, is critical to the generation of wealth, increased economic activity and economic diversification. "Research-based innovation is about expanding our ability to create new wealth", they say, and to further illustrate the complementary relationship between knowledge management and innovation, they comment (2000: 6) on the synergy between innovation and knowledge management, maintaining that knowledge capital is the "primary driver of innovation dynamics that create and maintain superior innovating power". For an enterprise to sustain this, it must be able to move beyond its existing paradigms and mindsets to meet the demands 
of competition and the growing needs for multidisciplinary knowledge.

Nonaka and Takeuchi (1995), relate the successes of post-World War II Japanese industry to the uncertainty in the environment within which the Japanese had to compete. While corporations like General Motors and IBM were becoming more complacent on account of their certainty of dominance in the market, the Japanese firms, struggling against international competition, could not afford the same complacency. One approach to equalising their position was making a conscious decision to strive towards their set objectives by means of continuous innovation. One innovation led to another, with the concomitant improvement and upgrading, as illustrated by the Japanese automobile industry. In leveraging lower labour costs, the Japanese were able to build new modern plants. They ultimately became masters in the application of innovative processes like Just in Time (JIT) logistics and Total Quality Management (TQM), which allowed them to become competitive in the global automobile industry.

Creativity is not innovation (Skyrme, 1998), and many enterprises create difficulties when they try to equate innovation with invention. Skyrme (2000: 1) quotes Amidon's opinion that innovation is "the creation, evolution, exchange and application of new ideas into marketable goods and services for the success of an enterprise, the vitality of a nation's economy, and the advancement of society". This emphasises the conversion of ideas into commercial applications, the springboard for which is the creation of an idea. Effective knowledge management and knowledge creation thus become precursors to innovation.

In terms of the knowledge economy and innovation, Murray and Rowan (2000: 2) maintain that research-based innovation is of critical importance to the knowledge economy because it generates increased economic activity, wealth and improved environmental conditions. They further maintain that "research-based innovation is about expanding our ability to create new wealth and improve social conditions, with win-win outcomes". They go on to say that, as determinants for success, human capital and

research information, collectively referred to as "knowledge capital", are the primary drivers of the innovation dynamics that create superior innovating power. The enterprise must reach beyond its internal resources so that they are augmented by specialists and consultants in a multi-disciplinary approach.

As the global economic environment becomes increasingly competitive, successful enterprises are concentrating more on their ability to "know what the enterprise knows", and then extracting this knowledge, turning it into ideas and transforming them into more rapid product innovation processes and new markets. Innovative processes are a natural progression to the establishment of incubation as a possible approach, in which knowledge, knowledge management, knowledge creation and innovation are encapsulated and managed in order to improve an enterprise's competitive advantage.

3

\section{Business incubation}

Roussel (2001: 1) defines a business incubator in the following way: "The term incubator is used to describe high-tech business clusters, the role of which is to pool resources to provide 'brick and mortar' facilities, hands-on help, personal connections and expertise. These clusters sometimes provide the seed funding needed for early stage start-up".

Lepeak (2000: 2) defines an eBusiness incubator as “.... a service organisation (individual or virtual) that provides a full-service range to design, deploy, and potentially operate an [eBusiness] offering post-incubation...". Some of the services offered include advisory, funding, design, construction and operations. The ultimate goal is to build an entity able to rapidly (within weeks) develop an idea into a deployed initiative.

Duff's definition (1999: 11) of a business incubator is comprehensive. It describes the incubator's characteristics and adds specific critical dimensions to describe its design and benefits: "A business incubator may be defined as an organisation which offers a range of 
business development services and access to small space on flexible terms, to meet the needs of new firms. The package services offered by a business incubator are designed to enhance the success and growth rates of new enterprises, thus maximising their impact on economic development."

This definition makes it clear that a systematic approach is used in the development of a venture by means of an incubator, that business consultants are involved, entrepreneurial synergy becomes key, affordable working space must be provided and office services are shared in order to reduce costs. This fulfils the five critical dimensions cited by Duff in his definition. In summary, all the definitions offered emphasise a controlled environment, the use of technology, the need to change the incubator model to suit the time-to-market requirement, the availability of space, specialised resources and, in some cases, the need for seed funding or access to capital.

Incubators have been in use since the early 1940s, and have evolved into a number of incubator and hybrid models. They were initiated in the academic fraternity, to be used for incubating student enterprises. In the early 1950 s they were introduced into industry, specifically as an approach to job creation. The trend in applying incubators as a development tool became popular in the 1980 s and early 1990s as a way of assisting the development of fledgling small businesses. The use of incubators was regarded as a means of ensuring a greater measure of success than was attributed to more conventional models. The approach did, however, start to lose some of its appeal as doubts were cast on its effectiveness as a global economic development tool (Gonzales \& Lucea, 2001).

The Millennium Group (2000: 5) provides an insight into the decision that should be made by any enterprise on the choice between pursuing an in-house incubator (corporate incubator) and investing in an external stand-alone incubator. According to the Millennium Group, the advantages of a corporate incubator are:

- the flow of new ideas at the heart of core business
- maintaining interest and commitment on the part of valuable employees attracted by things entrepreneurial

- access to core business services supporting a full range of incubator activities

- networking access throughout the business to customers, suppliers, distributors and employees

- better management control over the incubator's performance

- access to corporate resources.

The services rendered by a corporate incubator are part of its value for the venture. Such services may certainly be obtainable from sources outside the incubator, but a "package" service offering constitutes a more general approach. Chinsomboon (2000: 43) lists a number of these offerings:

- Infrastructure: This can relate to the "instanton" office rendering access and support in terms of communications, printing and furniture. But, most importantly, it is a facility where the participants can meet, formally or informally, to discuss issues at hand and exchange ideas. Typically, experts in their respective fields are also made available to assist the incubator's ventures. Back-office arrangements and technology are also provided.

- Partnerships: It is essential for an incubator without a track record to have some form of partnership to assist in initial networking. Typical partners and affiliates are banks, law and accounting firms and consultants.

- Technology: This is the provision of hightechnology equipment, a testing and programming environment, and software. When it comes to technology, the venture must take care to manage and safeguard its intellectual property.

- Recruiting and human resources: This is considered one of the most important services of an incubator, especially in respect of senior-level staff, often acquired in liaison with a specialised recruiting agency. 
- Community-network of contacts: A feature common to all the various incubator models is that they are focused on developing a network of enterprises, contacts and complementary products, all of which can be used to assist one another within the network.

\section{4}

\section{The establishment of an eBusiness incubator in Eskom}

The energy industry is undergoing considerable changes, which include competition, regulatory change, liberalisation and price pressures. These are key issues for energy players, applying no less to Eskom, the fourth largest electricity utility in the world.

Gas and electricity markets in Europe and the USA are already undergoing significant transformation, driven by multiple forces with infrastructure, markets and technology. In South Africa, Eskom is faced with the state-sponsored restructuring of its electricity distribution industry, the linked privatisation initiatives for its power stations and the threat from natural gas, which has entered its existing markets. Legislation changes, third-party access to the electricity grid like the South African Power Pool, privatisation, competition, globalisation, gas and electricity convergence and newgeneration technology all pose both challenges and opportunities to Eskom. The net result is that deregulation in South Africa will, as in the USA, unbundle the existing utilities value chain, while Internet technologies help to define business challenges.

Top management of Eskom decided that eBusiness could have the following impact on the corporation in its use of:

- Internet technology to streamline operational efficiencies within the current business model;

- Internet technology to build closer links between customers and suppliers, and to provide value-added services;

- Internet technology to redefine the value chain and break the rules governing buying, selling and producing.
Eskom's establishment of an incubator project was based on a combination of the non-profit and venture approaches, in which an incubator was established, commonly referred to as the eBusiness Programme Office (eBPO). A number of facilitated work-group sessions were held to obtain as much input as possible from stakeholders. This summarised information was then discussed with external consultants and supplemented by documentary sources. The results were summarised and a Delphi technique approach applied to obtain a strategic plan, which was presented to the Eskom Information Strategy Board and subsequently approved. Eskom decided to follow a method based on the corporate incubator model, to be appropriately adapted to suit Eskom's current and future needs.

Eskom's use of this adapted model begs the question regarding the relationship between knowledge creation and incubation as an approach to innovation. Vaux (2001: 4) refers to"knowledge work", a term originally coined by Prusak and Davenport. In qualifying the content and extent of knowledge work, Vaux (2001: 4) quotes Morello and the Gartner Groups as saying, "Knowledge work entails the creation, transformation, integration and analysis of data, information, individual knowledge and knowledge culled from other sources to generate value-added products and services".

Morello's view is extended to establish the relationship between knowledge creation and innovation in the incubation process. He maintains that examples of knowledge work are, inter alia, consulting, business incubation, entrepreneurship and advanced technology development.

The following major issues facing Eskom were highlighted (Eskom, 2002: 25):

- What are our customers and competitors doing about eBusiness?

- How will eBusiness change the structure of our markets?

- Where are the potential threats to our business from intomediaries and/or competitors, and what can be done to minimise their impact? 
- Should we be adopting a leading or a following strategy?

- What opportunities should we be pursuing?

- Are we doing everything possible to improve efficiencies and add value to customer relationships?

- Are the foundational structures of our business culture and business process in place?

- Should we set up a separate eBusiness, or should we change our current business models?

- Are we building flexibility into our systems and business architecture to deal with an uncertain future, and building environmentsensing capabilities?

- What capabilities do we need to develop, what type of partnerships should we build and what activities should we source?

- Is everyone in the enterprise aligned with the plans?

The facility, now operational for six years, has completed a number of innovative, viable projects, most of which have either been implemented or are in the process of being implemented by the business. This success must be attributed to the level of pre-research done, the professionalism in establishing the incubator and the credibility of the results achieved.

\section{5}

\section{Empirical survey}

The purpose of the empirical survey was to determine first whether the corporate incubator model applied by Eskom, and referred to as the eBusiness Programme Office (eBPO), conformed with the attributes of knowledge management, knowledge creation and innovation. Secondly, it had to be determined whether the exploitable synergies in these disciplines could be harnessed to give Eskom a competitive advantage.

\subsection{Methodology}

Little research has been done on the relationships between knowledge management, innovation and corporate incubators. Consequently, the available research is largely incomplete, reports are scarce and methods of studying the subject(s) vary (Christensen \& Tan, 2000). It was therefore decided to use Grounded Theory in the empirical survey, since this can be used if there exists no general theory on the phenomenon. Grounded Theory produces concepts that can be related or applied to the phenomenon and in fact "intimately" describes the phenomenon being studied (Bajaj, 1998: 11). The advantage of this is that a number of concepts can be identified and a clearer view obtained on the factors per concept that play a role. Further, the participants themselves generate the factors, placing the responsibility for analysis on the researcher.

When deciding on the sample population to be used, the incubator considered applied resources from the following segments of contributors:

- Eskom resources employed in the actual day-to-day application of some of the functionality researched;

- subject matter experts from both the enterprise and external sources, such as consultants;

- Eskom senior management, whose interest was directed at the potential results to be achieved.

A population of 46 Eskom employees was selected on the basis of their close involvement with Eskom's incubator (the eBPO) over the previous two years. A group of 18 individuals was randomly chosen. They received a questionnaire (see Appendix A) and a request for their participation in the research. Ten individuals from this group of 18 agreed to participate. Respondents 1, 2 and 3 had been involved with the eBPO since its inception, while the remaining respondents had been involved either in the design stages or during the project initiation phases.

The questionnaires were forwarded by email to the respondents, who were requested to complete the questions to the best of their ability within two weeks. Following this, personal interviews of about 30 minutes' duration were 
held with all the respondents. During the interviews, care was taken to avoid pointing out any new information to the respondents. Nothing was recorded on tape because of objections by some of the respondents. Notes were kept on information relating to salient details and on responses to the prepared questions, and were typed immediately after the interview.

The responses to the questionnaires were then placed on a spreadsheet according to the sub-problem investigated, with the respondents' answers next to each other. This was to facilitate the data analysis phase, referred to as the "memoing" stage. Any additional information obtained during the interview was included afterwards as part of a respondent's original response, which provided a more complete picture of that respondent's observations.

\subsection{Findings}

\section{(a) Observations by the respondents on knowledge management and innovation}

The respondents' views on knowledge management and innovation were collated from both the questionnaires and the subsequent individual in-depth interviews. The information given by respondents was grouped into "Categories" and "Concepts", as shown in Table 1.

\section{Table 1}

Categories, concepts, and broad definitions emerging from the respondents' observations on knowledge management and innovation

\begin{tabular}{|c|c|c|}
\hline Categories & Concepts & Broad definition \\
\hline $\begin{array}{l}\text { Knowledge } \\
\text { management } \\
\text { context }\end{array}$ & $\begin{array}{ll}\text { - } & \text { Knowledge } \\
\text { management } \\
\text { - } & \text { Synergy } \\
\text { - } & \text { Paradigm shift }\end{array}$ & $\begin{array}{l}\text { The KM context refers to the importance of the knowledge- } \\
\text { based economy and all its attributes and requirements. } \\
\text { Knowledge and innovation are complementary processes } \\
\text { and the synergy obtained when they are managed together } \\
\text { is critical to the process of generating wealth, economic } \\
\text { activity and economic diversification. A paradigm shift is } \\
\text { required by enterprises to achieve the required state of } \\
\text { sensitivity and incorporation of KM to meet the demands } \\
\text { of competition and the growing need for multi-disciplinary } \\
\text { knowledge. }\end{array}$ \\
\hline $\begin{array}{l}\text { Innovation } \\
\text { context }\end{array}$ & - Continuous innovation & $\begin{array}{l}\text { Continuous innovation is a never-ending process of } \\
\text { improvement that is consciously and publicly supported by } \\
\text { senior management. }\end{array}$ \\
\hline $\begin{array}{l}\text { Enterprise } \\
\text { environment } \\
\text { context }\end{array}$ & $\begin{array}{l}\text { - Certainty vs } \\
\text { uncertainty }\end{array}$ & $\begin{array}{l}\text { Uncertainty in the enterprise's environment is a creative } \\
\text { force, as opposed to complacency, which may be } \\
\text { brought about by a state of certainty in an enterprise's } \\
\text { environment. }\end{array}$ \\
\hline $\begin{array}{l}\text { Management } \\
\text { context }\end{array}$ & - Coding of knowledge & $\begin{array}{l}\text { The ability of an enterprise to extract and apply knowledge } \\
\text { to the advantage of the enterprise. }\end{array}$ \\
\hline $\begin{array}{l}\text { Knowledge } \\
\text { conversion } \\
\text { context }\end{array}$ & $\begin{array}{l}\text { - Tacit and explicit } \\
\text { knowledge }\end{array}$ & $\begin{array}{l}\text { The conversion process and the situational context used to } \\
\text { convert tacit knowledge to explicit knowledge. }\end{array}$ \\
\hline
\end{tabular}

The determination of the context for a specific category was based on an area common to the observations of the majority of the responses. The categories range from a macro-perspective, such as the knowledge management context, to more specific issues like the actual conversion process of converting tacit knowledge to explicit knowledge.

Knowledge management is a broad subject and the respondents were required to take a narrow 
view in terms of how it should be managed, what is expected from the individual and how it is partnered with innovation. There was general agreement by the respondents on the factors within each context and the role(s) of the factor(s).

\subsection{Knowledge management context}

The questions and subsequent discussions focused on whether knowledge is viewed as a basis for economic growth rather than on the provision of goods as the primary economic factor. They also focused on potential organisational changes by the enterprise to accommodate knowledge management.

The respondents accepted the importance of knowledge and its increasing role in industry, agreeing that it would impose a review of enterprise organisational levels. However, they disagreed on the extent of the move away from primary production factors as the basis for economic growth.

The respondents' views reflect those of Burton-Jones (1999) and Drucker (1998). Burton-Jones is of the opinion that the demarcation between services and goods is increasingly less distinct, seeing that knowledge is becoming the outstanding characteristic of economic activity. Drucker (1998) refers to the need of the information-based enterprise for specialists in its operational areas to perform its activities. Consequently, the enterprise must respond appropriately through an organisational structure that has to accommodate these newlyrequired skills and resources with a concomitant reduction in organisational levels and faster intra-enterprise communication.

According to one respondent, "without knowledge, innovation is difficult, hence the synergy". Another respondent mentioned: "Without knowledge management there can be no innovation. You first have to realise the opportunity before you can be innovative with reference to a better solution". Murray and Rowan (2000) agree that knowledge and innovation are complementary issues, and that synergy is obtained with the realisation that knowledge capital is the primary driver of innovation dynamics that create and sustain innovation. The two authors refer to knowledge being the primary driver of innovation and that, in maintaining this driving force, the enterprise must move beyond existing paradigms and mindsets to meet the demands of competition. The respondents viewed such a paradigm shift more as a quantum change in thinking and strategy. They did agree, however, that the change had to be of such a magnitude that only the notion of a paradigm shift could accommodate it.

\subsection{Innovation context}

One respondent stated that "[c]ontinuous innovation is what got the Japanese where they are today, as they had to compete with the large Western firms like General Electric". Another said,"To ensure that continuous innovation takes place there needs to be a continuous 'burning platform'. The 'burning platform' is something that drives people and organisations to change. While incentivising new ideas works for a short period, there needs to be a constant element that will continuously identify and communicate 'burning platforms' within the organisation".

The first respondent's observation on continuous innovation accords with Quinn's view (in Amidon,1999: 2). There is a reference to the role of senior management involvement and its provision of the required resources to support continuous innovation. The observation on a "burning platform" acting as a trigger is valid, but this can succeed only if top management is involved. The ability of management to simultaneously sustain a number of continuous "burning platforms" is doubtful, but the process of communication and elevation of the issues to create a more permanent momentum accords with Quinn's opinion (in Amidon, 1999: 2).

\subsection{Enterprise environment context}

The way in which the enterprise views, reacts to and attempts to influence its environment directly affects the ability of the enterprise to strategically ensure its survival. One respondent equated uncertainty with incremental improvements, while another referred to complacency as an opportunity for a shake-up in a certain industry. The issue here is that the industry may be so 
complacent as to not realise what is happening in its environment, so its opportunity may never arise.

\subsection{Management context}

The management context relates to whatever conscious steps the enterprise takes to ensure that the knowledge available to it from within is extracted. The coding of knowledge refers to the specific steps that can be taken by management in the enterprise to extract that knowledge from its employees. Murray (1999: 14) refers to an elusive form of knowledge, experiential knowledge, and the difficulty of extracting this form of knowledge and applying it to the advantage of the enterprise. Coding of this knowledge can be done through the creation of an appropriate environment, "sense-and-response" models, or the use of teams. All the respondents alluded in some way to aspects of Murray's views. They perceived a need for management involvement and a favourable environment created specifically to extract experiential knowledge. There was an understanding that knowledge management takes cognisance of the requirements of the business and aligns whatever knowledge is available or required. If managed well, knowledge is leveraged to alleviate further work production and knowledge creation.

\subsection{Knowledge conversion context}

There are two major players in the knowledge conversion process, the individual and the context within which the conversion process takes place. The respondents agreed with both Skyrme (1999) and Nonaka and Takeuchi (1995) in this respect. The latter provide for two levels of knowledge conversion, that is, the individual and the context or infrastructure to facilitate this, which is provided by the enterprise. Nonaka and Takeuchi (1995: 59) specifically state that knowledge conversion is “...created dynamically and in social interaction among people...". Their perspective was supported in the respondents' observations in terms of the social nature of the process.

\section{(a) Respondents'observations on the list of attributes influencing the manage- ment of innovation in an enterprise}

Management of innovation in the enterprise poses a number of issues to be addressed by both management and the employees involved. The analysis of the respondents' observations and a comparison of the applicable literature reflect a close agreement on the importance of areas like the enterprise culture and the role of management. There was general agreement that innovation is a structured sequential process of planned activities that must comply with specific business parameters and that require both qualitative and quantitative measurements.

The respondents' comments on those attributes that, according to them, will influence the management of innovation in an enterprise were summarised from the comments on returned questionnaires and the notes taken during the personal interviews.

Five major categories were identified as common to the majority of the respondents' observations (see Table 2). It is of interest to note that already, at this early stage of the research analysis, a number of categories common to those identified for the category on knowledge management and innovation were again identified, that is, environmental aspects, the role of management and the innovation approach or process. 
Table 2

Categories, concepts and broad definitions: The factors that may influence the management of innovation in an enterprise

\begin{tabular}{|c|c|c|}
\hline Categories & Comments & Broad definition \\
\hline $\begin{array}{l}\text { Environmental } \\
\text { context }\end{array}$ & $\begin{array}{l}\text { - } \\
\text { - } \text { Customironment } \\
\text { - Opportunity-exploitation }\end{array}$ & $\begin{array}{l}\text { This is the environment within the enterprise } \\
\text { that should promote a common vision i.r.o. } \\
\text { innovation, and should allow for opportunities to } \\
\text { be recognised and exploited. Also an environment } \\
\text { which is focused on customer and service delivery } \\
\text { orientation. }\end{array}$ \\
\hline $\begin{array}{l}\text { Organisational } \\
\text { culture context }\end{array}$ & $\begin{array}{ll}\text { - } & \text { Risk tolerance } \\
\text { - } & \text { Reward system }\end{array}$ & $\begin{array}{l}\text { The organisational culture of the enterprise must } \\
\text { allow for risk-tolerance, failure and recovery } \\
\text { from failure. A management team that rewards } \\
\text { experimentation and breakthrough innovation. } \\
\text { Out-of-the-box thinking is encouraged. }\end{array}$ \\
\hline $\begin{array}{l}\text { Innovation process } \\
\text { context }\end{array}$ & $\begin{array}{ll}\text { - } & \text { Structured process } \\
\text { - } & \text { Strategic planning }\end{array}$ & $\begin{array}{l}\text { A process that allows for recognition of } \\
\text { opportunities to be formalised through a filtering } \\
\text { process. It ensures that the enterprise allocates } \\
\text { resources and funding to the initiatives. Application } \\
\text { of further validation processes to the innovation/ } \\
\text { opportunity and, if successful, the incorporation of } \\
\text { the innovation into the enterprise's overall strategic } \\
\text { plan for delivery. }\end{array}$ \\
\hline $\begin{array}{l}\text { Leadership and } \\
\text { management } \\
\text { context }\end{array}$ & $\begin{array}{ll}\text { - } & \text { Commitment } \\
\text { - } & \text { Skills development } \\
\text { - } & \text { Intrapreneurship }\end{array}$ & $\begin{array}{l}\text { A demonstrated strong commitment from } \\
\text { management to any innovation programme. } \\
\text { Development of skills to recognise and utilise } \\
\text { opportunities. The selection of intrapreneurs within } \\
\text { the enterprise and assisting them by means of } \\
\text { training and guidance to exploit their potential to } \\
\text { the fullest. Ensure that the day-to-day operations } \\
\text { of the enterprise do not inhibit the innovation } \\
\text { process. }\end{array}$ \\
\hline $\begin{array}{l}\text { Measurement } \\
\text { context }\end{array}$ & - Quantitative measurements & $\begin{array}{l}\text { There should be a process for measuring in } \\
\text { quantitative terms the impact of the innovation. }\end{array}$ \\
\hline
\end{tabular}

\subsection{Environmental context}

This discussion focused on what is required in the internal environment of the enterprise to enable conditions conducive to the achievement of sustainable innovation. The respondents' observations distinctly encompassed Wycoff's (2002) account, which requires three primary aspects to be in place for effective innovation in an enterprise. These are the presence of a common vision, the recognition and use of opportunities and the effective movement towards achieving objectives. Eskom can face these challenges by increasing its efficiencies. Knowledge management increases an enterprise's efficiency by identifying, capturing, and then disseminating and using the knowledge that is most critical to it.

\subsection{Organisational culture context}

This context relates to the activities undertaken by the enterprise to encourage a corporate culture supportive of innovation. According to the respondents, an enterprise should have a culture in which employees feel that they can submit new ideas, that their ideas will not be "stolen" and that there will be appropriate recognition. Effective knowledge 
management processes are linked closely with user commitment to the knowledge management initiative. For this reason, many knowledge management initiatives focus on changing entrenched cultures of knowledge-hoarding and isolationism. However, culture-change is not sufficient. While it attempts to inspire a vision of better things, the processes themselves reveal the required changes in behaviour. It is therefore essential that clearly-defined, easily-executed business processes supplement such change. Processes and policies must be defined as enabling mechanisms for knowledge management solutions, as they determine the ultimate quality of knowledge-sharing and thus its usefulness.

\subsection{Innovation process context}

The respondents were required to reflect on the nature and structure of an innovation process. A number of them indicated that a sequential process should be applied. Some observations were more complete than others, but, in the main, they indicated that a formal, wellmanaged process is a pre-requisite if innovation is to succeed. The responses agreed with the process postulated by Chen and Ho (2002), in that the respondents saw the innovative process as being formalised, which, by implication, also means that the process is robust, requiring a distinctive output.

\subsection{Leadership and management context}

Leadership and the role of management were strongly emphasised. It was generally agreed that, without extensive management involvement and demonstrated leadership support, an innovative environment would not be achieved in an enterprise. Wycoff (2002) refers to specific initiatives in the enterprise and, inter alia, to the development and communication of an innovation-based vision to everyone in the enterprise. This is possible only under conditions driven by the enterprise's executive team and senior management. The respondents' observations are supported by this view. Dynamic leadership by the enterprise's management is an indispensable pre-requisite for successful innovation in an enterprise.

\subsection{Measurement context}

In this category, only two respondents referred directly to the requirements for quantitative rather than qualitative measurements. They were clear as to the difference between assessment, which uses more qualitative data, and measurement, which applies quantitative data. The low frequency of reference by respondents is a point of concern, as the only manner in which management can be appraised objectively in respect of results is through the measuring of and reporting on quantitative criteria and performance. It is essential that both the impact and the direction of an innovation be measured as they have a direct correlation with the complexity of the management of that innovation (Chen \& Ho, 2002).

\section{(a) Respondents' observations on the attributes required for the success of a corporate incubator}

In this section, the respondents commented on what they regarded as and have experienced to be the successful attributes of a corporate incubator.

The respondents made observations on incubator models, the organisational culture that could be considered conducive to incubator ventures, the role of management and what the enterprise should have in place to improve the creativity process. A number of common categories were again analysed, for example, the role of management and the environment, as well as the potential impact of organisational culture on the success of the incubator (see Table 3). 
Table 3

Categories, concepts, and broad definitions: The attributes necessary for the success of a corporate incubator

\begin{tabular}{|c|c|c|}
\hline Categories & Concepts & Broad definition \\
\hline Incubator model & $\begin{array}{l}\text { - } \text { Venture model } \\
\text { - } \text { Corporate model } \\
\text { - Funding } \\
\text { - Risk }\end{array}$ & $\begin{array}{l}\text { The question arises as to which of the models best } \\
\text { suits the in-house corporate incubator scenario. } \\
\text { Where does the funding originate and what risk } \\
\text { does it impose on the enterprise as well as on the } \\
\text { incubator? }\end{array}$ \\
\hline $\begin{array}{l}\text { Organisational } \\
\text { culture context }\end{array}$ & $\begin{array}{l}\text { - } \text { Conduciveness } \\
\text { - Inhibiting }\end{array}$ & $\begin{array}{l}\text { Organisational culture may inhibit or promote the } \\
\text { desired functions and contributions of the incubator } \\
\text { and where it promotes such a culture it may play a } \\
\text { role in enhancing its ability to deliver as desired. }\end{array}$ \\
\hline $\begin{array}{l}\text { Management } \\
\text { context }\end{array}$ & - Management support & $\begin{array}{l}\text { The role played by top and senior management } \\
\text { in facilitating the potential deliverables and } \\
\text { contributions on an in-house incubator. }\end{array}$ \\
\hline $\begin{array}{l}\text { Harnessing } \\
\text { creativity }\end{array}$ & $\begin{array}{l}\text { - } \quad \text { "Special" means } \\
\text { - Physical }\end{array}$ & $\begin{array}{l}\text { "Special" means relate to whatever is put in place } \\
\text { by the enterprise to ensure that creative talent is } \\
\text { identified, ideas extracted and creativity put to the } \\
\text { test. This also includes the establishment of physical } \\
\text { infrastructure, which is regarded as facilitating the } \\
\text { motivation of the resources in the incubator venture. }\end{array}$ \\
\hline
\end{tabular}

\subsection{Incubator model}

The questions posed and discussions carried out on an incubator model focused on two issues: first, determining whether the respondent was au fait with the different models generally in use, and secondly, the actualities of incubator operations. The respondents stated correctly that the corporate incubator is restricted to an enterprise only, whereas the venture incubator, for example, is aligned with whoever funds it and that entity's objectives. The respondents' views on the origins of funding as a distinguishing factor were correct in terms of Chinsomboom's segmentation (2000).

\subsection{Organisational culture context}

Commenting on the enterprise's cultural environment, within which an incubator has to function and deliver, the respondents mentioned issues like the extensive role of management, the development of resources, support services, the concept of school fees as well as the emphasis on being allowed to experiment, fail, recover and try again. One respondent also expressed the view that, while it may be "dangerous", employees could be motivated by participation in the incubation process of their own ideas, but that this needed to be managed.

\subsection{Management context}

The management context refers to the role of top and senior management in the enterprise. It also refers to their role in supporting the incubator and alignment of the enterprise, enabling the incubator to achieve the desired results. All the respondents referred to the extensive role of top and senior management in actively supporting the incubator's efforts.

\subsection{Harnessing creativity}

Harnessing creativity requires the input of various factors, which have to be managed if optimum conditions for creativity are to be achieved. Such conditions encompass aspects ranging from the management of human resources, reward systems and "emotional" motivation to the requirements of physical infrastructure. Respondents reflected on the 
role of the employees in the incubator and the management of these resources.

\subsection{Respondents' observations of Eskom's incubator (the $e$ BPO)}

This section relates directly to observations on issues concerning the eBPO. It is essential, from a qualitative perspective, to access respondents' thinking as well as to apply it as an evaluation/assessment measure to the eBPO. While the eBPO was originally thought to be a temporary institution for facilitating the implementation of eBusiness in Eskom, its basic tenets, methodology, structure and operations may be incorporated into a "New Business Development" (NBD) incubator concentrating on all forms of new business developments. Respondents' views may thus also be indispensable to the planning for this possible new venture, and are discussed in terms of the general issues applicable to the eBPO (see Table 4).

Table 4

Categories, concepts and broad definitions: the eBPO

\begin{tabular}{|l|l|l|}
\hline Categories & Concepts & Broad definition \\
\hline Process context & $\begin{array}{l}\text { Logical and } \\
\text { executable process }\end{array}$ & $\begin{array}{l}\text { The process and methodologies employed by the } \\
\text { eBPO should conform to best practices and should be } \\
\text { changed if they do not. }\end{array}$ \\
\hline Opportunities context & - Opportunity analysis & $\begin{array}{l}\text { The eBPO was presented with a number of } \\
\text { opportunities for evaluation. Did the evaluation take } \\
\text { place? Were those with the best possible contribution } \\
\text { to operational efficiencies selected? }\end{array}$ \\
\hline Cultural context & $\begin{array}{l}\text { Cultural appropriate- } \\
\text { ness }\end{array}$ & $\begin{array}{l}\text { Did the culture and the environment of the eBPO } \\
\text { contribute to its successes? In what way? }\end{array}$ \\
\hline Competitive context & $\begin{array}{l}\text { Contribution of } \\
\text { projects }\end{array}$ & $\begin{array}{l}\text { Did the projects produced by the eBPO have a } \\
\text { significant impact on Eskom's competitiveness? }\end{array}$ \\
\hline $\begin{array}{l}\text { Commercialisation } \\
\text { context }\end{array}$ & $\begin{array}{l}\text { External commercial } \\
\text { potential }\end{array}$ & $\begin{array}{l}\text { There may be a requirement for the eBPO to become } \\
\text { a commercial entity. Respondents' views on the } \\
\text { potential for or likelihood of success were sought. }\end{array}$ \\
\hline
\end{tabular}

\subsection{Process context}

The process context relates to the processes instituted by the eBPO to ensure that it delivers according to expectations. The respondents generally agreed that the applied processes and methodologies are logical and executable. Handing over an initiative to the business for execution is a critical component of the process.

\subsection{Opportunities context}

The eBPO process was designed to evaluate opportunities presented to it in an orderly manner. The objective was to gain a quick response as to whether or not the idea submitted related to Eskom's strategic intent, and whether it was seen as a viable opportunity. If this phase had a positive outcome, the idea would be developed in accordance with the processes followed by the eBPO. Respondents agreed that the eBPO had done excellent work so far, but that the focus on ideation and further acceleration through top management support held even more opportunities.

\subsection{Cultural context}

Respondents noted a number of cultural issues, which have been dealt with in the previous sections. The respondents have all been exposed to the prevailing culture in the eBPO, which is one that allows anyone to present their views, 
and ensures that the observation(s) are analysed and acted on.

\subsection{Competitive context}

The eBPO launched a number of eBusiness initiatives in Eskom. The major projects are Catalogue eProcurement, on-line forms, an eLearning pilot, a customised online approach to the Application of the Promotion of Access to Information Act, a number of mobile commerce applications, information strategy benefits, realisation measurement tools, the commercialisation of an Application Services Provider and major research into online energy trading and online procurement applications.

Respondents' perceptions of the contribution of these projects were noted. All the projects taken forward had positive business cases and had been approved by the appropriate authorities for implementation. Respondents commented that the versatility of a corporate incubator is adequately illustrated in terms of the range of projects undertaken, most of which require completely different approaches and, to an extent, different technologies, especially mobile commerce applications.

\subsection{Commercialisation context}

The commercialisation context reviews the respondents' observations on the possibility of moving the eBPO into initiatives external to Eskom and on behalf of non-Eskom clients. There appeared to be qualified consensus amongst the respondents that the eBPO indeed has the potential for commercialisation in the longer term.

\section{6}

\section{Conclusion}

In the knowledge economy, markets transform or become obsolete so rapidly that prominence in any particular market segment could actually be detrimental to survival. Key to the knowledge economy is the ability to reinvent the business and innovate constantly. A corporate incubator entity combines knowledge management, creation and innovation and, if designed and managed appropriately, affords the enterprise an initiative that could prepare it for becoming or remaining competitive in the marketplace. A corporate incubator is also of value as an employee-retention strategy, allowing intrapreneurs in the enterprise to contribute both their ideas and their subsequent involvement in projects to enhance the competitive position of the enterprise.

Knowledge management goes beyond technology with professional skills development programmes, retreats, open-door policies, focus groups, "drumming and rainmaking" sessions that encourage the creation of new knowledge, sharing existing experience and expertise, and the efficient utilisation of these assets for the benefit of all. Thus knowledge management allows employees to work more efficiently, because it is concerned with addressing the allocation of resources within an enterprise and improving overall profitability.

Because of economic pressures and market trends, Eskom increasingly has to engage in strategic thinking about business growth and development, which, to a great extent, involves managing people and their expertise. But if the competitive business model involves deployment of the enterprise's knowledge assets, then simply recognising the importance of knowledge is not enough. It also has to define the unique scope of knowledge and understand its properties and relational value. If value is to be derived from these assets, Eskom needs to know where it resides, as well as how to provide leverage and diffuse it in ways that cannot easily be replicated by competitors.

In many enterprises people are so busy that they do not have time to share and collaborate. Knowledge is time-sensitive and loses value quickly, so shortage of it is a serious impediment to the unrestricted flow of knowledge. Coupled with this, the nature of work might also be a stumbling block. Eskom employees are frequently out of their offices, which leaves them fewer opportunities of interacting with colleagues. Along with the limited time available, the absence of co-location might further prevent people from sharing their knowledge.

The achievements of the eBPO at Eskom support the contention that it is a successful 
attempt at fast-tracking projects in a complex corporate environment. This was also borne out by respondents' comments in this study. This research was limited to the eBPO as a single example of a corporate incubator. The entity incorporates most of the attributes discussed in the literature, and a more realistic view might have been achieved had another, similar, incubator been researched. However, this would have been difficult, as enterprises in a competitive position do not make public any information on their initiatives.

Eskom is of the opinion that effective knowledge management and knowledge creation become precursors to innovation. Key to the success of any knowledge management initiative is the need to link knowledge processes to specific business objectives that are recognised as providing distinct benefits or significant value to the business. Knowledge work, unlike more traditional types of labour, has proved resistant to re-engineering attempts and process innovation. For knowledge to be fully functional, it must be provided within a framework. Eskom therefore needs well-defined knowledge-capture processes. Employees should know where and how to contribute relevant new knowledge, as well as what happens to that knowledge consequent to their contribution. There should be different processes and channels, depending on the level or type of knowledge shared.

The shift to knowledge as the centre of wealth production has alerted the senior leadership of most large enterprises to the necessity of developing better techniques for managing this vital asset. An enterprise-wide knowledge management initiative is complex, because it attempts to create processes, systems and incentives that cut across organisational boundaries, encouraging employees to share what they know. This also optimises the existent knowledge assets within the enterprise. One of the most complex issues for any knowledge management initiative lies in identifying and prioritising which of these knowledge assets to manage first and how to do so. If Eskom is to be successful, a knowledge-management initiative must be driven by an understanding of the strategic value that will be added to the enterprise. While explicit knowledge can be distributed through a variety of media, the same cannot be said for tacit knowledge, which is heavily reliant on the creation of shared understanding among individuals. The conversion of tacit into explicit knowledge usually leads to a less rich knowledge exchange.

As the global economic environment becomes more competitive, successful enterprises are concentrating more on their ability to "know what the enterprise knows", to extract this knowledge, turn it into ideas and transform them into more rapid product innovation processes and new markets.

\section{References}

1 AMIDON, D.M. (1999) "Ten definitions of innovation", Available from: http://www. entovation.com/innovation/10definitions.htm (Accessed 14 February 2004).

2 BAJAJ, A. (1998) Factors Relevant to Senior Information Systems Managers' Decisions to Adopt New Computing Paradigms: An Exploratory Study. Carnegie Mellon University: Pittsburgh, PA.

3 BURTON-JONES, A. (1999) Knowledge Capitalism: Business, Work and Learning in the New Economy. Oxford University Press: Oxford.

4 CHEN, E.L. \& HO, K.K. (2002) Demystifying Innovation, Cap Gemini Ernst \& Young Centre for Business Innovation.

5 CHINSOMBOON, O.M. (2000) "Incubators in the new economy", Available from: http://www. chinsomboon.com/incubator, (Accessed 11 November 2003).

6 CHRISTENSEN, C.A. \& TAN, A. (2000) "Developing ideas for innovative products", Available from: http://www.kiss.dk/innovation/ FinalReport.pdf, (Accessed 9 October 2003).

7 DRUCKER, P.F. (1998) Harvard Business Review on Knowledge Management, Harvard Business School Publishing: Boston.

8 DUFF, A. (1999) "Best practice in business incubator management", Available from: http:// www.wantree.com.au/ aduff/ (Accessed 5 January 2005).

9 ESKOM. (2002) "The e in Eskom: eBusiness overview and framework". Unpublished presentation.

10 FIRESTONE, J.M. (2003) Enterprise Information Portals and Knowledge Management, ButterworthHeinemann: London.

11 GONZALEZ, M. \& LUCEA, R. (2001) "The evolution of business incubation", Available from: 
http://www.heinz.cmu.edu/ced/topics/t3inc1/incub1. html (Accessed 12 January 2004).

12 LEPEAK, S. (2000) "Incubate this! Hatching a dot-com. Meta Group, Available from: http:/ clients.metagroup.com/cgi-bin/inetcgi/search/ displayArticle. isp?oid=12334 (Accessed 15 October 2004).

13 MILLENNIUM GROUP. (2000) "Discovery 2000. briefing paper 8 . corporate innovation \& internet incubators", Available from: http://www.millenn. co.uk/ Reports/Corplnn.pdf (Accessed 9 December 2003).

14 MURRAY, P. (1999) "How smarter companies get results from KM", Business Day, Mastering information management series, Part 6. Financial Times: Johannesburg.

15 MURRAY, J. \& ROWAN, E. (2000) "Partnership for innovation and knowledge transfer", Available from: http://www.spottedcowpress.ab.ca/km/pdfs/ 09Rowan Murray.pdf (Accessed 2 February 2004).

16 NONAKA, I. \& TAKEUCHI, H. (1995) The Knowledge-Creating Company, Oxford University Press: Oxford.
17 ROUSSEL, A. (2001) Incubators: The Law of Diminishing Returns, Gartner. Note Number: SPA13-4393.

18 SKYRME, D.J. (1998) "Creativity and innovation”, Available from: http://www.skyrme. com/updates/u17.htm (Accessed 24 March 2005).

19 SKYRME, D.J. (1999) Knowledge Networking: Creating the Collaborative Enterprise, ButterworthHeinemann: Oxford.

20 SKYRME, D.J. (2000) "Innovation: Knowledge connections", Available from: http://www.skyrme. com/site/innov.htm (Accessed 21 April 2005).

21 VAUX, J. (2001) "Knowledge as power": A critical survey of claims for a knowledge revolution". (Draft document) Paper prepared for ESA, Stream Technologies; 1/9/01, Helsinki 2001.

22 WYCOFF, J. (2002) "Defining innovation", Available from: http://www.speaking. com/articles htm/JoyceWycoff_224.html (Accessed 5 January 2004). 


\section{Appendix A}

\section{Questionnaire on Knowledge Management}

1. What is your opinion on whether there is a movement away from the provision of the production of goods to knowledge as the basis for growth?

2. Will knowledge constitute a change in organisational structure towards recognition and search for the Knowledge Management (KM) worker, i.e. a more substantive transition from manual workers to knowledge workers?

3. Strategic 'research-based innovation' is about expanding an enterprise's ability to create new wealth. What do you understand by this? Where do you see synergy between innovation and knowledge management?

4. Do you believe enterprises need new paradigm shifts and management approaches to meet the demands for obtaining synergy between KM and innovation?

5. In the enterprise environment:

Does certainty play a role - the more uncertain the future the more innovative as opposed to complacency?

What do you think needs to be in place to ensure that continuous innovation takes place?

6. What do you understand by the phrase "conversion of tacit knowledge to explicit knowledge"?

7. Do you think that it is a social, formal, informal or a combination of all of these conversion processes?

8. If an enterprise is to have a KM strategy what should be the end-objective of such a strategy?

9. The process of innovation refers to the conversion by the enterprise of selected opportunities into successful products and or services.

In your view:

What factors in the enterprise environment play a contributory role to the achievement of successful innovation?
What are the factors that play a role in the innovation process?

What role does the culture of an enterprise play in the innovation process?

What are your thoughts on the role of management in the innovation process?

10. There are various models and forms of incubation. Where do you see the corporate incubator in relation to models like the Venture Capital incubator?

11. Do you think incubators are the new business models? Are they here to stay?

12. In your opinion, which factors underlying the corporate culture of an enterprise are prerequisites for the strategic acceptance of the requirement of a corporate business incubator in the enterprise?

13. You are au fait with Eskom as an enterprise and its strategic imperatives. In terms of your perspective of this, is the general Eskom environment conducive to such an incubation venture, or does it inhibit its potential success? What is the rationale supporting your argument?

14. How important is an enterprise's ability to provide "special" means for creative talent/ ideas to be harnessed to ensure that

- the employee is allowed to test out his creativity

- potential creativity is turned into a commercial opportunity

- the employee's role is recognised, not necessarily in terms of monetary awards?

15. What do you think is the role of top management in the establishment and subsequent operation of a corporate incubator?

16. You are au fait with the process as applied in the eBPO, or at least with most of its phases. 
- In your opinion, does the sequential nature of activities constitute a logical process?

- Did Eskom utilise the opportunities presented by the process to the greatest practical extent?

- What needs to be changed? Why?

- Did those employees who wanted to present new views or ideas have the opportunity to do so, for instance, by means of the ProcureZone activity?
- Will the results of some of the projects, if successfully completed by the eBPOI, make a significant contribution to Eskom's competitive advantage?

- What is your view on the potential for successfully commercialising the eBPO and for it to undertake work external to Eskom? 